\title{
Non-specific elevation of serum Mac-2 binding protein glycosylation isomer levels in patients with biliary disease
}

\author{
TADAYUKI TAKAGI ${ }^{1}$, REI SUZUKI ${ }^{1}$, MITSURU SUGIMOTO ${ }^{1}$, NAOKI KONNO ${ }^{1}$, YUKI SATO ${ }^{1}$, HIROKI IRIE ${ }^{1}$, \\ KO WATANABE ${ }^{1}$, JUN NAKAMURA ${ }^{2}$, MIKA TAKASUMI ${ }^{1}$, TAKUTO HIKICHI ${ }^{2}$ and HIROMASA OHIRA ${ }^{1}$ \\ Departments of ${ }^{1}$ Gastroenterology and ${ }^{2}$ Endoscopy, Fukushima Medical University \\ School of Medicine, Fukushima 960-1295, Japan
}

Received June 13, 2018; Accepted October 10, 2018

DOI: $10.3892 / \mathrm{mco} .2018 .1750$

\begin{abstract}
The aim of the present study was to clarify the clinical significance of a novel fibrotic marker, serum Mac-2 binding protein glycosylation isomer (M2BPGi), in non-cirrhotic patients with biliary diseases. Associations between the serum levels of M2BPGi and clinical features (including background disease and laboratory data) were analyzed. A total of 78 patients with biliary disease (32 with biliary cancer and 46 with benign disease) were evaluated, and their clinical features (age, sex and biliary stricture status), serum level of M2BPGi and other serum laboratory data [aspartate aminotransferase (AST), alanine aminotransferase (ALT), $\gamma$-glutamyltranspeptidase $(\gamma$-GTP), alkaline phosphatase (ALP), total bilirubin (TB), direct bilirubin (DB), c-reactive protein $(\mathrm{CRP})$, carcinoembryonic antigen (CEA) and carbohydrate antigen 19-9 (CA19-9)] were compared. In addition, correlations between the serum level of M2BPGi and other laboratory data were also evaluated. The median serum M2BPGi was increased in cases of biliary tumor [cut-off index (COI), 1.91] compared with cases of benign disease (COI, 0.73; $\mathrm{P}<0.0001)$. All biliary cancer cases presented with biliary strictures, and 5 patients had liver metastases. Cases with liver metastases exhibited higher M2BPGi levels compared with cases without liver metastases (COI, 3.75 vs. 1.53; $\mathrm{P}=0.008$ ). The level of M2BPGi was correlated with levels of AST, ALT, $\gamma$-GTP, ALP, TB, DB, CRP, CEA and CA19-9. In conclusion, the serum M2BPGi level could be non-specifically elevated, particularly in non-cirrhotic patients with biliary stricture.
\end{abstract}

Correspondence to: $\mathrm{Dr}$ Tadayuki Takagi, Department of Gastroenterology, Fukushima Medical University School of Medicine, 1 Hikarigaoka, Fukushima 960-1295, Japan

E-mail: daccho@fmu.ac.jp

Key words: Mac-2 binding protein glycosylation isomer, biliary cancer, biliary obstruction

\section{Introduction}

Since development of Mac-2 binding protein glycosylation isomer (M2BPGi) as a new serum biomarker for liver fibrosis by Kuno et al (1), it is now recognized as the most precise predictor of liver fibrosis in chronic hepatitis as well as liver cirrhosis compared with conventional fibrotic markers, such as the FIB-4 index and hyaluronic acid $(1,2)$. The presence of M2BPGi also may predict the presence of hepatocellular carcinoma in patients with cirrhosis $(3,4)$. Since many studies using M2BPGi have been conducted targeting liver diseases, the marker may be misled as a specific for liver disease. However, recent studies have indicated that M2BPGi is positively correlated with biliary abnormalities (increased biliary enzymes and bile duct damage) in patients with primary biliary cirrhosis (PBC) and primary sclerosing cholangitis (PSC) $(5,6)$. These results implied a potential non-specific elevation of serum M2BPGi level in patients with biliary disease.

In the current study, the aim was to clarify changes in serum M2BPGi levels in non-cirrhotic patients with biliary diseases.

\section{Materials and methods}

Patients and sample collection. Between April 2015 and December 2017, serum was prospectively collected from 78 patients with pancreaticobiliary diseases. Additionally, stored serum of 30 healthy volunteers was used as control. All cancer cases were pathologically confirmed. Patients with a history of chronic liver disease were excluded as such diseases can affect the serum level of M2BPGi, as previously described (1-4). Written, informed consent was obtained from all patients and healthy volunteers. The study protocol conformed to the ethical guidelines of the 1975 Declaration of Helsinki and was approved by the Institutional Review Committee of Fukushima Medical University (Fukushima, Japan).

Patient clinical data, including age, sex, serum M2BPGi level and other serum laboratory data [aspartate aminotransferase (AST), alanine aminotransferase (ALT), $\gamma$-glutamyltranspeptidase $(\gamma$-GTP), alkaline phosphatase (ALP), total bilirubin (TB), direct bilirubin (DB), c-reactive protein (CRP), carcinoembryonic antigen (CEA) and carbo- 
hydrate antigen 19-9 (CA19-9)] were obtained from electronic medical records. Blood samples were collected after obtaining informed consent, then immediately processed to separate the serum and stored at $-20^{\circ} \mathrm{C}$.

Measurement of M2BPGi levels. Serum (0.4 ml) was sent to a company (LSI Medience Corporation, Tokyo, Japan) and the levels of M2BPGi in serum were measured with a sandwich immunoassay as previously described $(1,2)$. Briefly, glycosylated M2BP was captured by Wisteria floribunda agglutinin (WFA) that was immobilized on magnetic beads. The bound product was assayed with an anti-human M2BP monoclonal antibody linked to alkaline phosphatase. Two reagent packs (M2BP-WFA detection pack and a chemiluminescence substrate pack, Sysmex, Kobe, Japan) were loaded into an HISCL-5000 automated immunoassay machine (Sysmex, Kobe, Japan). The detection pack comprised three reagents: A reaction buffer solution (R1), a WFA-coated magnetic bead solution (R2) and an ALP-aM2BP solution (R3). The chemiluminescence substrate reagent pack contained a CDP-Star substrate solution (R4) and a stopping solution (R5). Typically, serum (10 ml) was diluted to $60 \mathrm{ml}$ with $\mathrm{R} 1$ and then mixed with R2 $(30 \mathrm{ml})$. Following the binding reaction, $\mathrm{R} 3(100 \mathrm{ml})$ was added to the reaction solution. The resultant conjugates were magnetically separated from unbound components, and mixed well with $\mathrm{R} 4(50 \mathrm{ml})$ and $\mathrm{R} 5(100 \mathrm{ml})$ prior to reading of the fluorescence. The chemiluminescent intensity was acquired within $17 \mathrm{~min}$ of the aforementioned procedure. All counts were standardized and converted to a cut-off index (COI) for M2BPGi (1).

Statistical analysis. Continuous variables (age and serum CEA, CA 19-9, M2BPGi, AST, ALT, ALP, $\gamma$-GTP, TB and $\mathrm{DB})$ are reported as the median (interquartile range) values, and were compared with the Mann-Whitney U test. Sex and the presence of biliary stricture were compared with Fisher's exact probability tests. Correlations between laboratory data and M2BPGi were analyzed with Spearman's correlation analyses. Data are presented as the median and interquartile range. All statistical analyses were performed with GraphPad Prism 6.0 (GraphPad Software, Inc., La Jolla, CA, USA). $\mathrm{P}<0.05$ was considered to indicate a statistically significant difference.

\section{Results}

We included 32 with biliary cancer (median age: 72.5 year-old, 22 male and 10 female) and 46 with benign diseases (median age: 69.5 year-old, 35 male and 11 female) in this study (Table I). While there were no significant differences in age and $\operatorname{sex}(\mathrm{P}=0.05$ and $\mathrm{P}=0.13$, respectively), all laboratory data values were increased in patients with a biliary tumor compared with the benign controls (Table II).

Among all 78 patients, the serum M2BPGi level was positively correlated with all variables (AST, ALT, ALP, TB and DB levels, and $\gamma$-GTP, CRP, CEA and CA 19-9 levels; Table III). On the other hand, among 32 cases of biliary cancer, serum M2BPGi level was not correlated with ALT, $\gamma$-GTP, CRP, CEA or CA 19-9 levels. Additionally, among 46 cases of benign disease, serum M2BPGi level was not correlated with TB, CEA or CA 19-9 levels.

M2BPGi was increased in patients with biliary strictures (COI, 1.36 vs. 0.53; $\mathrm{P}<0.0001$; Fig. 1A) and liver metastases (COI, 3.75 vs. 1.53 ; $\mathrm{P}=0.008$; Fig. 1B) compared with cases without those findings. In benign disease, no significant difference was identified in the serum level of M2BPGi between 15 patients with biliary stricture and 31 patients without biliary stricture (COI, 0.77 vs. $0.70 ; \mathrm{P}=0.85$; Fig. $1 \mathrm{C}$ ), while the levels were higher in cases of benign disease compared with healthy volunteer controls (COI, 0.46; $n=30$; $\mathrm{P}=0.01$; Fig. 1D).

\section{Discussion}

In the current study, changes in serum M2BPGi levels in biliary diseases were investigated and identified to be increased, along with the levels of abnormal hepatobiliary enzymes, in both biliary tumor and benign biliary disease cases. Additionally, the proportion of patients with extrahepatic biliary stricture/obstruction was higher in patients with biliary tumors compared with patients without biliary strictures (100 vs. 32\%; $\mathrm{P}<0.001)$. To the best of our knowledge, this was the first study to report a non-specific elevation of serum M2BPGi levels in non-cirrhotic patients.

The source of M2BPGi had been uncertain until Bekki et al (7) first demonstrated that hepatic stellate cells (HSCs) may be a source of M2BPGi in liver cirrhosis. To clarify which liver cell subpopulation secreted M2BPGi, the group measured M2BPGi levels in the cell culture supernatant of primary HSCs, Kupffer cells, hepatocytes, biliary epithelial cells and endothelial cells, and identified that HSCs secreted M2BPGi. The group also identified that M2BPGi secreted from HSCs induced expression of Mac-2 in Kupffer cells, which in turn activated HSCs to be fibrogenic. These results could also explain the elevated M2BPGi levels in other chronic hepatobiliary diseases, including PSC and PBC, in which activation of HSCs has been observed $(8,9)$. Activation of HSCs is also induced during acute liver injury and biliary obstruction (10-12). This could explain why M2BPGi levels are increased in patients with biliary diseases.

Furthermore, M2BPGi levels could be elevated in fibrosis of other organs, including the heart (13), lung (14) and pancreas (15). Pancreatic ductal adenocarcinoma also exhibited elevated M2BPGi levels compared with other pancreaticobiliary diseases, which may reflect the desmoplastic reaction in pancreatic ductal adenocarcinoma (16). This might be a reason why the serum levels of M2BPGi in benign disease controls which included several pancreatitis patients were higher than healthy controls.

The present study was limited by the relatively small number of samples that were collected at a single institution. Further studies with a larger number of patients are required to consolidate the results of this preliminary study.

In conclusion, M2BPGi levels may be increased by biliary obstruction. Therefore, elevated M2BPGi levels should be interpreted carefully if patients with cirrhosis present with concomitant diseases that may have an effect on M2BPGi elevation. 
Table I. Clinical characteristics of patients.

\begin{tabular}{|c|c|c|c|}
\hline Characteristic & $\begin{array}{l}\text { Benign disease } \\
\qquad(\mathrm{n}=46)\end{array}$ & $\begin{array}{l}\text { Biliary cancer } \\
\qquad(\mathrm{n}=32)\end{array}$ & P-value \\
\hline Age (years), median (IQR) & $69.5(64.0-79.0)$ & $72.5(66.7-80.5)$ & 0.05 \\
\hline $\operatorname{Sex}(M / F)$ & $35 / 11$ & $24 / 10$ & 0.13 \\
\hline Background disease, (n) & $\begin{array}{l}\text { Bile stone (21) } \\
\text { Chronic pancreatitis (18) } \\
\text { Autoimmune pancreatitis (4) } \\
\text { Not specified (3) }\end{array}$ & Cholangiocarcinoma (32) & NA \\
\hline Biliary stricture, n (\%) & $15(32)$ & $32(100)$ & $<0.001$ \\
\hline Presence of liver metastasis, $\mathrm{n}(\%)$ & NA & $5(14.7)$ & NA \\
\hline
\end{tabular}

IQR, interquartile range; NA, not applicable.

Table II. Comparison of laboratory data between the benign disease and biliary cancer groups.

\begin{tabular}{|c|c|c|c|}
\hline Laboratory data & $\begin{array}{l}\text { Benign disease } \\
\quad(n=46)\end{array}$ & $\begin{array}{l}\text { Biliary cancer } \\
\qquad(\mathrm{n}=32)\end{array}$ & P-value \\
\hline $\operatorname{AST}(\mathrm{U} / \mathrm{L})$ & $24.0(18.7-56.3)$ & $91.5(50.0-131.0)$ & $<0.0001$ \\
\hline $\operatorname{ALT}(\mathrm{U} / \mathrm{L})$ & $22.5(14.7-61.8)$ & $108(50.7-194.5)$ & $<0.0001$ \\
\hline$\gamma$-GTP $(\mathrm{U} / \mathrm{L})$ & $87.0(29.0-313.0)$ & $544(230.8-1066.0)$ & $<0.0001$ \\
\hline ALP (U/L) & $293(192.8-602.8)$ & 918.5 (521.8-1789) & $<0.0001$ \\
\hline $\mathrm{TB}(\mathrm{mg} / \mathrm{dL})$ & $0.9(0.65-1.45)$ & $2.3(0.97-10.4)$ & 0.0003 \\
\hline $\mathrm{DB}(\mathrm{mg} / \mathrm{dL})$ & $0.1(0.1-0.4)$ & $0.9(0.1-7.3)$ & 0.0019 \\
\hline $\mathrm{CRP}(\mathrm{mg} / \mathrm{dL})$ & $0.28(0.05-1.54)$ & $0.89(0.29-3.29)$ & 0.01 \\
\hline CEA (ng/ml) & $2.0(1.4-2.9)$ & $2.9(1.67-4.92)$ & 0.03 \\
\hline CA 19-9 (U/L) & $8.1(4.0-25.7)$ & $66.9(30.6-767.5)$ & $<0.0001$ \\
\hline M2BPGi (COI) & $0.73(0.41-1.1)$ & $1.91(1.0-2.7)$ & $<0.0001$ \\
\hline
\end{tabular}

Data are presented as the median (interquartile range). AST, aspartate transaminase; ALT, alanine transaminase; GGTP, $\gamma$-glutamyl transpeptidase; ALP, alkaline phosphatase; TB, total bilirubin; DB, direct bilirubin; CRP, c-reactive protein; CEA, carcinoembryonic antigen; CA19-9, cancer antigen 19-9; COI, cut-off index.

Table III. Correlation between serum Mac-2 binding protein glycosylation isomer levels and laboratory data in 78 patients with biliary diseases.

\begin{tabular}{|c|c|c|c|c|c|c|}
\hline \multirow{2}{*}{$\begin{array}{l}\text { Serum } \\
\text { laboratory data }\end{array}$} & \multicolumn{2}{|c|}{$\begin{array}{l}\text { All cases } \\
(n=78)\end{array}$} & \multicolumn{2}{|c|}{$\begin{array}{l}\text { Biliary cancer } \\
\qquad(\mathrm{n}=32)\end{array}$} & \multicolumn{2}{|c|}{$\begin{array}{l}\text { Benign disease } \\
\quad(n=46)\end{array}$} \\
\hline & rho & $\mathrm{P}$-value & rho & P-value & rho & $\mathrm{P}$-value \\
\hline AST & 0.53 & $<0.0001$ & 0.36 & 0.03 & 0.48 & 0.0008 \\
\hline ALT & 0.5 & $<0.0001$ & 0.18 & 0.30 & 0.39 & 0.007 \\
\hline$\gamma$-GTP & 0.52 & $<0.0001$ & 0.13 & 0.46 & 0.47 & 0.002 \\
\hline ALP & 0.66 & $<0.0001$ & 0.36 & 0.03 & 0.60 & $<0.0001$ \\
\hline TB & 0.47 & $<0.0001$ & 0.43 & 0.01 & 0.28 & 0.060 \\
\hline DB & 0.48 & $<0.0001$ & 0.41 & 0.01 & 0.35 & 0.020 \\
\hline CRP & 0.43 & 0.0001 & 0.28 & 0.11 & 0.41 & 0.006 \\
\hline CEA & 0.25 & 0.030 & 0.27 & 0.11 & -0.04 & 0.78 \\
\hline CA19-9 & 0.36 & 0.002 & 0.26 & 0.13 & 0.036 & 0.83 \\
\hline
\end{tabular}

AST, aspartate transaminase; ALT, alanine transaminase; GGTP, $\gamma$-glutamyl transpeptidase; ALP, alkaline phosphatase; TB, total bilirubin; DB, direct bilirubin; CRP, c-reactive protein; CEA, carcinoembryonic antigen; CA19-9. 
A

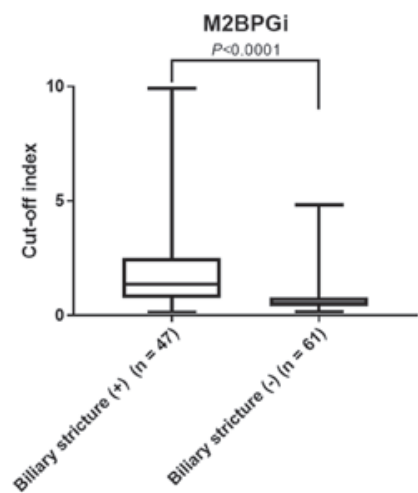

C

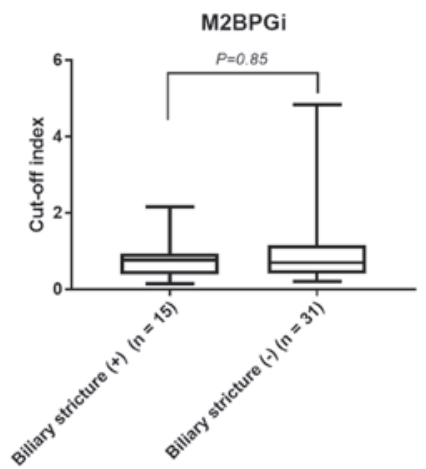

B

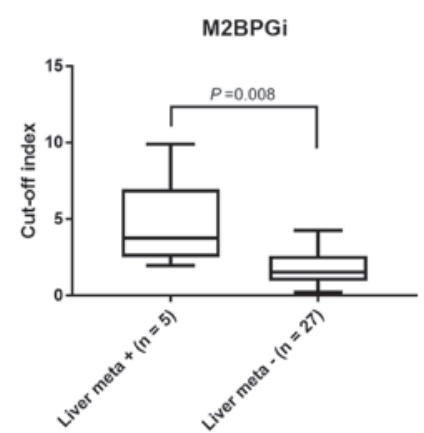

D

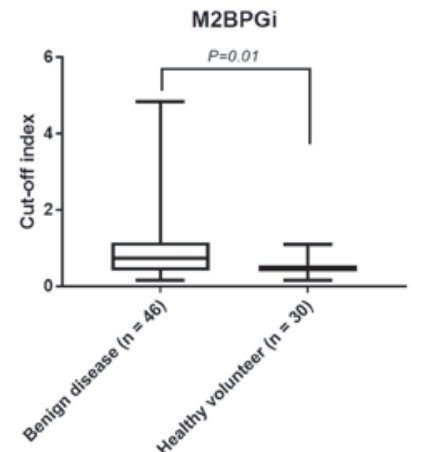

Figure 1. Serum M2BPGi levels in cases with biliary stricture and liver metastasis. (A) Median M2BPGi levels were increased in cases with biliary stricture compared with cases without stricture (COI, 1.36 vs. 0.53 ; $\mathrm{P}<0.0001$ ). (B) In biliary cancer, the median M2BPGi level is increased in cases with liver metastases compared with cases without metastases (COI, 3.75 vs. 1.53; $\mathrm{P}=0.008)$. (C) In benign disease, no significant difference was identified in the serum level of M2BPGi between 15 patients with biliary stricture and 31 patients without biliary stricture (COI, 0.77 vs. $0.70 ; \mathrm{P}=0.85$ ). (D) The levels were higher in cases of benign disease compared with healthy volunteer controls (COI, $0.46 ; n=30 ; \mathrm{P}=0.01$ ). Data are presented as the median and interquartile range. COI, cut-off index; M2BPGi, Mac-2 binding protein glycosylation isomer.

\section{Acknowledgements}

The authors would like to thank Ms. Chikako Saito and Ms. Rie Hikichi (Department of Gastroenterology, Fukushima Medical University School of Medicine, Fukushima, Japan) for their assistance during the experiments.

\section{Funding}

No funding was received.

\section{Availability of data and materials}

All data generated or analyzed during the present study are included in this published article.

\section{Authors' contributions}

TT, RS designed the experiment. TT, RS, MS, NK, YS, HI, $\mathrm{KW}, \mathrm{JN}, \mathrm{MT}, \mathrm{TH}$ and HO performed the experiments. TT and RS wrote the manuscript and analyzed the data.

\section{Ethics approval and consent to participate}

The present study was approved by the Institutional Review Committee of Fukushima Medical University School of Medicine (Fukushima, Japan; IRB no. 2387) and patients provided written informed consent.

\section{Patient consent for publication}

Not applicable.

\section{Competing interests}

The authors declare that they have no competing interests.

\section{References}

1. Kuno A, Ikehara Y, Tanaka Y, Ito K, Matsuda A, Sekiya S, Hige S, Sakamoto M, Kage M, Mizokami M, et al: A serum 'sweet-doughnut' protein facilitates fibrosis evaluation and therapy assessment in patients with viral hepatitis. Sci Rep 3: $1065,2013$. 
2. Narimatsu H: Development of M2BPGi: A novel fibrosis serum glyco-biomarker for chronic hepatitis/cirrhosis diagnostics. Expert Rev Proteomics 12: 683-693, 2015.

3. Toyoda H, Kumada T, Tada T, Kaneoka Y, Maeda A, Korenaga M, Mizokami M and Narimatsu H: Serum WFA ${ }^{+}-\mathrm{M} 2 \mathrm{BP}$ levels as a prognostic factor in patients with early hepatocellular carcinoma undergoing curative resection. Liver Int 36: 293-301, 2016.

4. Yamasaki K, Tateyama M, Abiru S, Komori A, Nagaoka S, Saeki A, Hashimoto S, Sasaki R, Bekki S, Kugiyama Y, et al: Elevated serum levels of Wisteria floribunda agglutinin-positive human Mac-2 binding protein predict the development of hepatocellular carcinoma in hepatitis $\mathrm{C}$ patients. Hepatology 60: 1563-1570, 2014

5. Umemura T, Joshita S, Sekiguchi T, Usami Y, Shibata S, Kimura T, Komatsu M, Matsumoto A, Ota M and Tanaka E: Serum Wisteria floribunda agglutinin-positive Mac-2-binding protein level predicts liver fibrosis and prognosis in primary biliary cirrhosis. Am J Gastroenterol 110: 857-864, 2015.

6. Umetsu S, Inui A, Sogo T, Komatsu H and Fujisawa T: Usefulness of serum Wisteria floribunda agglutinin-positive Mac-2 binding protein in children with primary sclerosing cholangitis. Hepatol Res 48: 355-363, 2018.

7. Bekki Y, Yoshizumi T, Shimoda S, Itoh S, Harimoto N, Ikegami T, Kuno A, Narimatsu H, Shirabe K and Maehara Y: Hepatic stellate cells secreting $\mathrm{WFA}^{+}-\mathrm{M} 2 \mathrm{BP}$ : Its role in biological interactions with Kupffer cells. J Gastroenterol Hepatol 32: 1387-1393, 2017.

8. Tahashi Y, Matsuzaki K, Date M, Yoshida K, Furukawa F, Sugano Y, Matsushita M, Himeno Y, Inagaki Y and Inoue K: Differential regulation of TGF- $\beta$ signal in hepatic stellate cells between acute and chronic rat liver injury. Hepatology 35: 49-61, 2002.

9. Williams EJ, Gaça MD, Brigstock DR, Arthur MJ and Benyon RC: Increased expression of connective tissue growth factor in fibrotic human liver and in activated hepatic stellate cells. J Hepatol 32: 754-761, 2000.
10. Iredale JP: Hepatic stellate cell behavior during resolution of liver injury. Semin Liver Dis 21: 427-436, 2001.

11. Koeppel TA, Trauner M, Baas JC, Thies JC, Schlosser SF, Post S, Gebhard MM, Herfarth C, Boyer JL and Otto G: Extrahepatic biliary obstruction impairs microvascular perfusion and increases leukocyte adhesion in rat liver. Hepatology 26: 1085-1091, 1997.

12. Morio K, Imamura M, Daijo K, Teraoka Y, Honda F, Nakamura Y, Kobayashi T, Nakahara T, Nagaoki Y, Kawaoka T, et al: Wisteria floribunda agglutinin positive Mac-2-binding protein level increases in patients with acute liver injury. J Gastroenterol 52: 1252-1257, 2017.

13. Okada A, Kanzaki H, Hamatani Y, Takashio S, Takahama H, Amaki M, Hasegawa T, Sugano Y, Yasuda S and Anzai T: Increased serum Wisteria floribunda agglutinin positive Mac-2 binding protein (Mac-2 binding protein glycosylation isomer) in chronic heart failure: A pilot study. Heart Vessels 33: 385-392, 2018.

14. Kono M, Nakamura Y, Oyama Y, Mori K, Hozumi H, Karayama M, Hashimoto D, Enomoto N, Fujisawa T, Inui N, et al: Increased levels of serum Wisteria floribunda agglutinin-positive Mac-2 binding protein in idiopathic pulmonary fibrosis. Respir Med 115: 46-52, 2016.

15. Fujiyama T, Ito T, Ueda K, Tachibana Y, Yasunaga K, Miki M, Takaoka T, Lee L, Kawabe K and Ogawa Y: Serum levels of Wisteria floribunda agglutinin-positive Mac-2 binding protein reflect the severity of chronic pancreatitis. J Dig Dis 18: 302-308, 2017.

16. Waragai Y, Suzuki R, Takagi T, Sugimoto M, Asama H, Watanabe K, Kikuchi H, Hikichi T, Masamune A, Kang Y, et al: Clinical significance of serum Wisteria floribunda agglutinin-positive Mac-2 binding protein in pancreatic ductal adenocarcinoma. Pancreatology 16: 1044-1050, 2016. 